\title{
The Impact of Self-Efficacy and Work Engagement on Healthcare Professionals' Proactive Behavior
}

\author{
Chrysovalantis Karagkounis ${ }^{1}$, Georgios Manomenidis ${ }^{2}$, Charalampos G. Platis ${ }^{3}$, \\ Evgenia Minasidou4, Thalia Bellali ${ }^{4}$
}

\author{
${ }^{1}$ Department of Social Welfare, Education and Equality, Municipality of Katerini, Katerini, Greece \\ ${ }^{2}$ Department of Orthopaedics General Hospital of Ptolemaida, Ptolemaida, Greece \\ ${ }^{3}$ Research and Studies Officer National School of Public Administration and Local Government, Athens, Greece \\ ${ }^{4}$ Department of Nursing, International Hellenic University, Thessaloniki, Greece \\ Email:kchrysov@gmail.com, george.mano@yahoo.gr,charisplatis@gmail.com, \\ eminasid68@gmail.com, bellalithalia@yahoo.com
}

How to cite this paper: Karagkounis, C. Manomenidis, G., Platis, C.G., Minasidou, E. and Bellali, T. (2020) The Impact of Self-Efficacy and Work Engagement on Healthcare Professionals' Proactive Behavior. Health, 12, 305-316

https://doi.org/10.4236/health.2020.124025

Received: March 16, 2020

Accepted: April 14, 2020

Published: April 17, 2020

Copyright $\odot 2020$ by author(s) and Scientific Research Publishing Inc. This work is licensed under the Creative Commons Attribution International License (CC BY 4.0).

http://creativecommons.org/licenses/by/4.0/

\begin{abstract}
Job crafting (JC) is a form of proactive behavior and refers to the initiatives employees that could take to change their tasks or other job characteristics to achieve the best person-job fit. JC consists of six dimensions: seeking structural and social job resources, as well as challenges, hindering job demands, optimizing job demands, and delegating tasks. The aim of the present study was to explore the impact of self-efficacy and work engagement on healthcare professionals' (HP) proactive behavior. A convenience sample of $295 \mathrm{HP}$ working in Primary and Secondary healthcare structures of Northern Greece completed a questionnaire that included: 1) demographic/occupational characteristics, 2) the Job Crafting Scale, 3) the Generalized Self-Efficacy Scale (GSE) and 4) the Utrecht Work Engagement Scale (UWES). Increased age was found to be associated with decreased levels of seeking social job resources $(p<0.01)$. Education level was positively associated with increased levels of seeking structural job resources $(p<0.01)$, seeking challenges $(p<$ 0.05 ), and optimizing job demands ( $\mathrm{p}<0.05)$, while job position was found to be negatively related to delegating tasks $(\mathrm{p}<0.01)$. Self-efficacy was positively associated with increased levels of seeking structural resources $(\mathrm{p}<0.001)$, challenges $(\mathrm{p}<0.001)$, and increased levels of optimizing job demands $(\mathrm{p}<$ 0.001 ), while it was positively associated with decreased levels of delegating tasks $(\mathrm{p}<0.05)$. In addition, increased work engagement was found to be associated with increased levels of seeking social job resources $(\mathrm{p}<0.05)$, challenges $(p<0.01)$, and optimizing job demands $(p<0.01)$. Findings highlight the importance of self-efficacy, work engagement and individual characteris-
\end{abstract}


tics in the realization of a resourceful work environment and HP' adjustment in the organization. Thus, interventions that promote HP' JC proactive behaviors should be encouraged.

\section{Keywords}

Job Crafting, Healthcare Professionals, Proactive Behavior, Self-Efficacy, Work Engagement

\section{Introduction}

In recent years, due to competition, economic crisis and rapid technological evolution, there has been a global shift from manufacturing economies to service and knowledge economies, which has dramatically changed the nature of work in organizations [1], especially in the healthcare sector. Therefore, work design theory and research highlight the importance of proactive behaviors of employees, such as job crafting. Job crafting (JC) refers to employees' perception about their work environment and the changes they might make to balance between workplace needs and their own preferences and values [2]. Recent studies indicate that job characteristics and individual factors, such as self-efficacy [3] [4] and work engagement [5], have a positive impact on employees' JC.

In multifaceted organizational constructs, such as the healthcare sector, individual characteristics (i.e. age, gender) and personal resources (i.e. self-efficacy) and, work engagement are often studied to better understand their impact on job performance and other positive organizational outcomes [6]. Many studies in fact, have shown that self-efficacy is positively related to work engagement [7] [8], while work engagement is linked with proactive behaviors [9] [10] [11].

Self-efficacy refers to individuals' expectations to produce desired behaviors and to successfully accomplish environmental changes [12]. Employees with high levels of self-efficacy use more appropriate coping and stress-management strategies in a more effective way, and are characterized by their efficiency to implement job resources [13]. Previous research in employees enrolled in a part-time master's of business administration (M.B.A.) program at a large urban university has shown that self-efficacy is positively related to proactive behavior, namely taking responsibility [14], to personal initiative [15] and proactive workplace behavior [16]. It also contributes to action readiness, positive change behavior [17], individual learning and goal achievement [18]. However, before adopting these proactive behaviors, employees evaluate the likely outcomes (costs and benefits) and the likely success [14].

Work engagement, is defined as "a positive, fulfilling, affective-motivational state of work-related well-being" [19], and according to Schaufeli \& Bakker [20], consists of three dimensions: "vigor" (high levels of energy and mental adaptability), "dedication" (pride, enthusiasm, sense of importance, inspiration) and "absorption" (complete concentration and absorption at work). The concept of 
work engagement refers to a continuous and pervasive work situation that does not refer to an object, person, event or behavior [20]. Work engagement is enhanced when individuals act proactively, namely when they are mobilized to seek challenges and effectively participate in problem solving [9]. Indeed, Ghitulescu [21] found a positive relationship between work engagement and JC in 164 employees of a Swedish car factory. In the light of the foregoing, we assume that the work engagement of healthcare professionals (HP) will be positively related to JC.

JC can be viewed in the light of the Job Demands-Resources model (JD-R) [22], because the employee who craft his/her job initiates changes in the level of job demands and job resources. According to this model developed by Tims et al. [2], four dimensions of JC in the workplace are defined: 1) seeking structural job resources, 2) seeking social job resources, 3) hindering job demands, and 4) seeking challenges. Two further dimensions were added (when and why) involving 5) optimizing job demands [23], and 6) delegating tasks [24].

The present study aims to investigate the impact of self-efficacy and work engagement on healthcare professional's JC. The choice of HP was based on the fact that a well-designed work environment in the health sector can directly affect both HP and patients [25].

\section{Method}

\subsection{Participants and Procedure}

A cross sectional study was conducted in Primary (health centers, local health units, rural and regional medical units) and Secondary healthcare structures (public hospitals) in Northern Greece from March to June 2019. A convenience sample of $295 \mathrm{HP}$ was considered eligible for the study (response rate $71.6 \%$ ). Inclusion criteria were at least one year of experience and a permanent employment status. Participants were orally invited to fill out the study questionnaire anonymously, accompanied by a description of the aim of the study. A ballot box was placed in each structure to collect the questionnaires. The study conforms to the principles outlined in the Declaration of Helsinki.

\subsection{Measures}

An anonymous battery of research tools was used with the following: 1) a demographic and occupational characteristics questionnaire, 2) the Job Crafting Scale, 3) the Generalized Self-Efficacy Scale, and 4) the Utrecht Work Engagement Scale.

\section{Job Crafting Scale (JC-Scale)}

The JC Scale [2] consists of 21 items and comprises of four dimensions/ sub-scales: "seeking structural job resources", "seeking social job resources", "seeking challenges", and "hindering job demands". In addition to the above 4 sub-scales, the new JC sub-scale "optimizing job demands" by Demerouti and Peeters [23] was used, which consists of 5 items. Finally, the JC sub-scale on 
"delegating tasks" [24] consists of 8 items. All the sub-scales of JC were adapted in Greek population [26] [27]. Cronbach's alpha for the sub-scales was 0.52 , $0.66,0.66,0.60,0.82,0.93$ respectively. For all sub-scales, a five-point rating scale was used $(1=$ never, 5 = always $)$.

\section{Self-Efficacy}

Self-Efficacy was assessed using the Generalized Self-Efficacy Scale (GSE) [28] and consists of 10 items (Cronbach's alpha $=0.75$ ). The total score is calculated by finding the sum of the all items. For the GSE, the total score ranges between 10 and 40, with a higher score indicating higher level of self-efficacy. The GSE has been translated and validated in Greek [29]. The response categories ranged from 1 (Not at all true) to 4 (Exactly true).

\section{Utrecht Work Engagement Scale}

Work engagement, including vigor, dedication and absorption, was assessed using the Utrecht Work Engagement Scale (UWES) [20], consisting of nine items, which has been evaluated in all cultures and across professions [30], and validated in Greek population [31]. Cronbach's alpha for both the sub-scales vigor and dedication was 0.84 , and for the sub-scale absorption was 0.81 . For all three sub-scales, a six-point rating scale was used $(1=$ never, $5=$ always $)$.

\subsection{Statistical Analysis}

Data analyses were carried out using the statistical package SPSS 24.0. Firstly, a descriptive analysis of each of the variables included in the study was performed. In order to assess the distributions of the data the Kolmogorov-Smirnov test of normality was used and $\mathrm{p}=0.05$ was considered significant. Since the regularity check showed no normal distribution of variables, non-parametric methods were used, such as Mann-Whitney for two independent sample tests, Kruskal Wallis for $\mathrm{k}$ independent samples. Also, bivariate analyses using Spearman's correlation coefficient were conducted to analyze how the variables were correlated. Finally, five multiple linear regression analyses have been carried out to analyze the effect of the predictive factors, such as demographic and occupational characteristics, self-efficacy and work engagement to JC proactive behaviors, such as seeking structural and social job resources, seeking challenges, optimizing job demands and delegating tasks (dependent variables).

\section{Results}

The convenience sample of the present study consisted of 295 HP with mean age 44.01 years. Demographic/Occupational characteristics of HP are presented in Table 1. Descriptive statistics for the three scales (self-efficacy, work engagement and JC) are presented in Table 2. Bivariate analyses between independent variables and JC proactive behaviors are presented in Table 3.

Multivariate linear regression analyses were applied for the identification of the predictive factors that were independently associated with JC proactive behaviors. 
Table 1. Demographic/Occupational characteristics of the HP.

\begin{tabular}{|c|c|}
\hline Characteristics & N (\%) \\
\hline \multicolumn{2}{|l|}{ Gender } \\
\hline Female & $243(82.4)$ \\
\hline Male & $52(17.6)$ \\
\hline Age & $44.01(8.05)^{\mathrm{a}}$ \\
\hline \multicolumn{2}{|l|}{ Marital status } \\
\hline Live with a partner/spouse & $171(58.8)$ \\
\hline Without partner/spouse (Single, Divorced, Widowed) & $120(41.2)$ \\
\hline \multicolumn{2}{|l|}{ Profession } \\
\hline Nurses/Nursing assistants & $235(79.7)$ \\
\hline $\begin{array}{l}\text { Other HP (residents and specialists doctors, psychologists, } \\
\text { social workers, physiotherapists) }\end{array}$ & $59(20.3)$ \\
\hline \multicolumn{2}{|l|}{ Educational level } \\
\hline Secondary education & $97(33)$ \\
\hline Tertiary education & $164(55.8)$ \\
\hline Master/Philosophy Doctorate (MSc/PhD) & $33(11.2)$ \\
\hline Working experience & $18.6(8.9)^{\mathrm{a}}$ \\
\hline Working experience in this structure & $11.3(9.1)^{\mathrm{a}}$ \\
\hline \multicolumn{2}{|l|}{ Job position } \\
\hline Department Heads/Supervisors & $28(9.5)$ \\
\hline Employees & $231(78.4)$ \\
\hline
\end{tabular}

a: Average (standard deviation).

Table 2. Means and standard deviations (SD) of scales and sub-scales.

\begin{tabular}{ccc}
\hline Scales and Sub-scales & Means & SD \\
\hline Self-efficacy & 27.01 & 4.34 \\
Vigor $(\mathrm{WE})$ & 7.98 & 2.84 \\
Dedication $(\mathrm{WE})$ & 8.31 & 3.04 \\
Absorption $(\mathrm{WE})$ & 7.74 & 2.85 \\
Seeking structural job resources $(\mathrm{JC})$ & 16.09 & 2.29 \\
Seeking social job resources $(\mathrm{JC})$ & 12.83 & 2.79 \\
Seeking challenges $(\mathrm{JC})$ & 14.49 & 2.69 \\
Hindering job demands $(\mathrm{JC})$ & 16.17 & 2.95 \\
Optimizing job demands $(\mathrm{JC})$ & 16.35 & 2.95 \\
Delegating tasks $(\mathrm{JC})$ & 14.76 & 6.27 \\
\hline
\end{tabular}

Notes: $\mathrm{WE}=$ Work engagement; JC $=$ Job crafting 
According to the results of the multivariate linear regression Table 4, marital status could predict seeking structural job resources. Level of education and self-efficacy were associated with increased levels of seeking structural job resources. Concerning seeking social job resources it was found that an increase in age was associated with decreased levels of this proactive behavior. However, an increase in the level of absorption (dimension of work engagement) was associated with increased levels of seeking social job resources (Table 5).

Multivariate linear regression Table 6 showed that increased levels of education, self-efficacy, and the two dimensions of work engagement (vigor and absorption)

Table 3. Summary table of correlations between quantitative and non-quantitative independent variables and JC behaviors.

\begin{tabular}{|c|c|c|c|c|c|c|}
\hline \multirow{2}{*}{$\begin{array}{l}\text { Independent } \\
\text { variables }\end{array}$} & \multicolumn{6}{|c|}{ Job Crafting (JC) behaviors } \\
\hline & $\begin{array}{l}\text { Seeking structural } \\
\text { job resources }\end{array}$ & $\begin{array}{l}\text { Seeking social job } \\
\text { resources }\end{array}$ & $\begin{array}{l}\text { Seeking } \\
\text { challenges }\end{array}$ & $\begin{array}{l}\text { Hindering job } \\
\text { demands }\end{array}$ & $\begin{array}{l}\text { Optimizing job } \\
\text { demands }\end{array}$ & Delegating tasks \\
\hline Age & 0.111 & $-0.203^{\star *}$ & 0.080 & 0.019 & $0.146^{*}$ & -0.071 \\
\hline Work experience & $0.134^{*}$ & $-0.121^{\star}$ & $0.163^{* *}$ & 0.064 & 0.142 & -0.004 \\
\hline $\begin{array}{l}\text { Work experience in } \\
\text { this structure }\end{array}$ & 0.086 & -0.120 & 0.110 & -0.019 & 0.092 & 0.038 \\
\hline Gender & 0.099 & 0.074 & 0.835 & 0.382 & 0.071 & $0.000^{* *}$ \\
\hline Marital status & $0.014^{*}$ & 0.234 & 0.737 & 0.121 & $0.001^{* *}$ & $0.001^{* *}$ \\
\hline Education level & $0.000^{* *}$ & 0.539 & $0.004^{* *}$ & 0.083 & $0.015^{*}$ & 0.691 \\
\hline Profession & 0.053 & 0.484 & 0.042 & 0.916 & 0.501 & 0.506 \\
\hline Job position & 0.206 & 0.170 & $0.010^{*}$ & 0.820 & 0.936 & $0.003^{* \star}$ \\
\hline Self-efficacy & $0.425^{\star *}$ & 0.062 & $0.364^{\star *}$ & 0.000 & $0.431^{* *}$ & $-0.210^{\star \star}$ \\
\hline Vigor (WE) & $0.322^{* *}$ & $0.142^{*}$ & $0.373^{* *}$ & -0.093 & $0.302^{* *}$ & $-0.202^{\star *}$ \\
\hline Dedication (WE) & $0.246^{\star *}$ & 0.101 & $0.237^{\star *}$ & $-0.164^{* *}$ & $0.211^{* *}$ & $-0.180^{\star *}$ \\
\hline Absorption (WE) & $0.208^{* *}$ & $0.185^{* *}$ & $0.331^{* *}$ & -0.086 & $0.163^{* *}$ & -0.027 \\
\hline
\end{tabular}

Notes: Significant Correlations at ${ }^{\star} p<0.05,{ }^{* *} p<0.01 ; \mathrm{WE}=$ Work engagement.

Table 4. Multivariate linear regression analysis for variables predicting seeking structural job resources.

\begin{tabular}{cccc}
\hline \multirow{2}{*}{ Independent variables } & \multicolumn{3}{c}{$R^{2}=0.276, F=13.20, p<0.001$} \\
\cline { 2 - 4 } & $\boldsymbol{\beta}$ & S.E. & $\mathrm{p}$ \\
\hline Work experience & 0.290 & 0.180 & 0.109 \\
Marital status & 0.024 & 0.207 & 0.921 \\
Education level & 0.558 & 0.198 & $<0.01$ \\
Self-efficacy & 0.176 & 0.031 & $<0.001$ \\
Vigor $(\mathrm{WE})$ & 0.093 & 0.074 & 0.206 \\
Dedication $(\mathrm{WE})$ & 0.047 & 0.072 & 0.514 \\
Absorption $(\mathrm{WE})$ & 0.026 & 0.67 & 0.694 \\
\hline
\end{tabular}

Notes: $\beta=$ Beta coefficient; S.E. $=$ Standard Error; $p=$ Two tailed statistical significance; WE $=$ Work engagement. 
were associated with increased levels of seeking challenges. Regression analysis revealed that an increase in the level of dedication (dimension of work engagement) was associated with decreased levels of hindering job demands $(\beta=$ $-0.144, p<0.01)$.

Increased levels of education, self-efficacy and work engagement were associated with increased levels of optimizing job demands Table 7. Finally, it was

Table 5. Multivariate linear regression analysis for variables predicting seeking social job resources.

\begin{tabular}{cccc}
\hline \multirow{2}{*}{ Independent variables } & \multicolumn{3}{c}{$R^{2}=0.071, F=4.88, p<0.001$} \\
\cline { 2 - 4 } & $\boldsymbol{\beta}$ & S.E. & $\mathrm{p}$ \\
\hline Age & -0.974 & 0.780 & $<0.01$ \\
Work experience & -0.022 & 0.380 & 0.946 \\
Vigor $(\mathrm{WE})$ & -0.018 & 0.083 & 0.829 \\
Absorption $(\mathrm{WE})$ & 0.170 & 0.080 & $<0.05$ \\
\hline
\end{tabular}

Notes: $\beta=$ Beta coefficient; S.E. $=$ Standard Error; $\mathrm{p}=$ Two tailed statistical significance; $\mathrm{WE}=$ Work engagement.

Table 6. Multivariate linear regression analysis for variables predicting seeking challenges.

\begin{tabular}{cccc}
\hline \multirow{2}{*}{ Independent variables } & \multicolumn{3}{c}{$\boldsymbol{R}^{2}=\mathbf{0 . 2 5 2}, F=10.50, p<0.001$} \\
\cline { 2 - 4 } & $\boldsymbol{\beta}$ & S.E. & $\mathrm{p}$ \\
\hline Work experience & 0.241 & 0.230 & 0.296 \\
Education level & 0.502 & 0.260 & $<0.05$ \\
Job position & -0.963 & 0.571 & 0.093 \\
Self-efficacy & 0.170 & 0.042 & $<0.001$ \\
Vigor $(\mathrm{WE})$ & 0.227 & 0.094 & $<0.01$ \\
Dedication $(\mathrm{WE})$ & -0.178 & 0.097 & 0.067 \\
Absorption $(\mathrm{WE})$ & 0.213 & 0.085 & $<0.01$ \\
\hline
\end{tabular}

Notes: $\beta=$ Beta coefficient; S.E. $=$ Standard Error; $p=$ Two tailed statistical significance; $\mathrm{WE}=$ Work engagement.

Table 7. Multivariate linear regression analysis for variables predicting optimizing job demands.

\begin{tabular}{cccc}
\hline \multirow{2}{*}{ Independent variables } & \multicolumn{3}{c}{$R^{2}=0.240, F=11.14, p<0.001$} \\
\cline { 2 - 4 } & $\boldsymbol{\beta}$ & S.E. & $\mathrm{p}$ \\
\hline Age & 0.436 & 0.281 & 0.122 \\
Marital status & 0.267 & 0.281 & 0.342 \\
Education level & 0.503 & 0.256 & $<0.05$ \\
Self-efficacy & 0.221 & 0.040 & $<0.001$ \\
Vigor $(\mathrm{WE})$ & 0.250 & 0.095 & $<0.01$ \\
Dedication (WE) & -0.021 & 0.094 & 0.826 \\
Absorption $(\mathrm{WE})$ & -0.031 & 0.091 & 0.733 \\
\hline
\end{tabular}

Notes: $\beta=$ Beta coefficient; S.E. $=$ Standard Error; $\mathrm{p}=$ Two tailed statistical significance; $\mathrm{WE}=$ Work engagement. 
Table 8. Multivariate linear regression analysis for variables predicting delegating tasks.

\begin{tabular}{cccc}
\hline \multirow{2}{*}{ Independent variables } & \multicolumn{3}{c}{$\boldsymbol{R}^{2}=\mathbf{0 . 1 2 7}, \boldsymbol{F}=\mathbf{5 . 4 2 , p < 0 . 0 0 1}$} \\
\cline { 2 - 4 } & $\boldsymbol{\beta}$ & S.E. & $\mathrm{p}$ \\
\hline Gender & 3.293 & 1.009 & 0.653 \\
Marital status & -0.689 & 0.606 & 0.257 \\
Job position & -4.036 & 1.349 & $<0.01$ \\
Self-efficacy & -0.192 & 0.100 & $<0.05$ \\
Vigor $(\mathrm{WE})$ & -0.198 & 0.220 & 0.370 \\
Dedication $(\mathrm{WE})$ & -0.050 & 0.200 & 0.802 \\
\hline
\end{tabular}

Notes: $\beta=$ Beta coefficient; S.E. $=$ Standard Error; $p=$ Two tailed statistical significance; $\mathrm{WE}=$ Work en gagement.

found that the job position was associated with reduced levels of delegating tasks Table 8. Similarly, an increase in the level of self-efficacy was associated with decreased levels of this proactive behavior.

\section{Discussion}

The findings of the present study indicate that age, level of education, job position, self-efficacy, and work engagement predict HP' JC proactive behaviors. Older HP was found to seek less for social job resources. These findings are in agreement with previous research in employees from different companies and across diverse job levels [6], in which older employees might not search for social resources due to already established work routines and network [32]. The positive relationship between level of education and seeking structural job resources, seeking challenges and optimizing job demands, was also identified in a similar study [33]. However, job position was found to be negatively related to delegating tasks. A possible explanation could be that participants in the present study considered delegating tasks as an administrative activity, which can only be implemented by supervisors or managers.

Self-efficacy had a positive relationship between seeking structural job resources, seeking challenges, and optimizing job demands. These findings are in line with previous research [15] [16], in which self-efficacy was related to employees' personal initiative in taking on responsibilities and additional tasks. Within this context, employees with high self-efficacy were found to seek more for structural resources, constructive demands and improvements in their work demands [14]. However, task assignment was found to be negatively related to self-efficacy. One possible explanation could be that self-efficacious employees do not delegate tasks to other colleagues because they believe in their abilities to carry out their tasks and achieve goals [18].

The positive association between work engagement and seeking challenges and optimizing job demands could be explained by the fact that employees with high levels of work engagement are more likely to achieve their work goals, thus 
enhance their sense of self-esteem by creating the conditions for adopting proactive JC behaviors [34]. However, dedication (dimension of work engagement) was negatively related to hindering job demands. According to Petrou et al. [35], hindering job demands may protect the employee's well-being in stress situations, and reduce the motivation or need for employees to act.

\section{Strengths and Limitations}

This study has two main strengths. The first is that good reliability scales were used. Second, it is that a battery of questionnaires with many sub-scales that evaluate many variables related to JC was used.

However, a number of limitations must be mentioned. First, data was obtained using self-reported measures, and participants may have answered the questionnaire in a socially desirable manner, which could have led to an overestimation of the true associations. Second, because of the convenience nature of sampling strategy (or because of the convenience sample of participants), generalizability of the current results to all $\mathrm{HP}$, or/and in other professions and sectors needs to be demonstrated.

Third, this study was cross-sectional in nature; therefore, we could not determine the causality between dependent variables and JC. Future studies among HP should try to replicate the present findings using an experimental or longitudinal design to establish.

\section{Conclusion}

Healthcare organizations that aim at creating a healthy work environment for employees should identify which factors promote positive proactive behaviors. Current evidence shows that self-efficacy and work engagement can contribute to HP' adoption of certain JC proactive behaviors. The present findings can be taken into account in work (re)design and in JC intervention programs.

\section{Acknowledgements}

This research is part of a larger study, which received the first award for "best work research study" entitled "Work redesign (job crafting) in the healthcare sector: A cross-sectional study" at the $1^{\text {st }}$ Conference of Nursing Service Hippocrates' General Hospital of Thessaloniki.

\section{Conflicts of Interest}

The authors declare no conflicts of interest regarding the publication of this paper.

\section{References}

[1] Grant, A.M. and Parker, S.K. (2009) Redesigning Work Design Theories: The Rise of Relational and Proactive Perspectives. The Academy of Management Annals, 3 , 317-375. https://doi.org/10.5465/19416520903047327 
[2] Tims, M., Bakker, A.B. and Derks, D. (2012) Development and Validation of the Job Crafting Scale. Journal of Vocational Behavior, 80, 173-186. https://doi.org/10.1016/j.jvb.2011.05.009

[3] Tims, M., Bakker, A.B. and Derks, D. (2014) Daily Job Crafting and the Self Efficacy-Performance Relationship. Journal of Managerial Psychology, 29, 490-507. https://doi.org/10.1108/JMP-05-2012-0148

[4] Niessen, C., Weseler, D. and Kostova, P. (2016) When and Why Do Individuals Craft Their Jobs? The Role of Individual Motivation and Work Characteristics for Job Crafting. Human Relations, 69, 1287-1313. https://doi.org/10.1177/0018726715610642

[5] Petrou, P., Demerouti, E., Peeters, M.C.W., Schaufeli, W.B. and Hetland, J. (2012) Crafting a Job on a Daily Basis: Contextual Antecedents and the Effect of Work Engagement. Journal of Organizational Behavior, 33, 1120-1141. https://doi.org/10.1002/job.1783

[6] Bipp, T. and Demerouti, E. (2015) Which Employees Craft Their Jobs and How? Basic Dimensions of Personality and Employees' Job Crafting Behaviour. Journal of Occupational and Organizational Psychology, 88, 631-655. https://doi.org/10.1111/joop.12089

[7] Xanthopoulou, D., Bakker, A.B., Demerouti, E. and Schaufeli, W.B. (2007) The Role of Personal Resources in the Job Demands-Resources Model. International Journal of Stress Management, 14, 121-141. https://doi.org/10.1037/1072-5245.14.2.121

[8] Xanthopoulou, D., Bakker, A.B., Demerouti, E. and Schaufeli, W.B. (2009a) Work Engagement and Financial Returns: A Diary Study on the Role of Job and Personal Resources. Journal of Occupational and Organizational Psychology, 82, 183-200. https://doi.org/10.1348/096317908X285633

[9] Hakanen, J.J., Perhoniemi, R. and Toppinen-Tanner, S. (2008) Positive Gain Spirals at Work: From Job Resources to Work Engagement, Personal Initiative and Work-Unit Innovativeness. Journal of Vocational Behavior, 73, 78-91. https://doi.org/10.1016/j.jvb.2008.01.003

[10] Salanova, M. and Schaufeli, W.B. (2008) A Cross-National Study of Work Engagement as a Mediator between Job Resources and Proactive Behaviour. The International Journal of Human Resource Management, 19, 116-131. https://doi.org/10.1080/09585190701763982

[11] Macey, W.H. and Schneider, B. (2008) The Meaning of Employee Engagement. Industrial and Organizational Psychology, 1, 3-30. https://doi.org/10.1111/j.1754-9434.2007.0002.x

[12] Bandura, A. (1997) Self-Efficacy: The Exercise of Control. WH Freeman/Times Books/Henry Holt \& Co., New York.

[13] Consiglio, C., Borgogni, L., Alessandri, G. and Schaufeli, W.B. (2013) Does Self-Efficacy Matter for Burnout and Sickness Absenteeism? The Mediating Role of Demands and Resources at the Individual and Team Levels. Work \& Stress, 27, 22-42. https://doi.org/10.1080/02678373.2013.769325

[14] Morrison, E.W. and Phelps, C.C. (1999) Taking Charge at Work: Extra Role Efforts to Initiate Workplace Change. Academy of Management Journal, 42, 403-419. https://doi.org/10.2307/257011

[15] Speier, C. and Frese, M. (1997) Generalized Self-Efficacy as a Mediator and Moderator between Control and Complexity at Work and Personal Initiative: A Longitudinal Field Study in East Germany. Human Performance, 10, 171-192. https://doi.org/10.1207/s15327043hup1002 7 
[16] Salanova, M., Llorens, S., Cifre, E., Martínez, I.M. and Schaufeli, W.B. (2003) Perceived Collective Efficacy, Subjective Well-Being, and Task Performance among Electronic Work Groups: An Experimental Study. Small Group Research, 34, 43-73. https://doi.org/10.1177/1046496402239577

[17] Schaubroeck, J. and Merritt, D.E. (1997) Divergent Effects of Job Control on Coping with Work Stressors: The Key Role of Self-Efficacy. Academy of Management Journal, 40, 738-754. https://doi.org/10.2307/257061

[18] van den Heuvel, M., Demerouti, E. and Peeters, M.C.W. (2015) The Job Crafting Intervention: Effects on Job Resources, Self-Efficacy, and Affective Well-Being. Journal of Occupational and Organizational Psychology, 8, 511-532. https://doi.org/10.1111/joop.12128

[19] Leiter, M.P. and Bakker, A.B. (2010) Work Engagement: An Introduction. In: Bakker, A.B. and Leiter, M.P., Eds., Work Engagement. A Handbook of Essential Theory and Practice, Psychology Press, London and New York, 1-9.

[20] Schaufeli, W.B. and Bakker, A.B. (2003) UWES-Utrecht Work Engagement Scale: Test Manual. Unpublished Manuscript, Department of Psychology, Utrecht University, Utrecht. https://doi.org/10.1037/t07164-000

[21] Ghitulescu, B.E. (2006) Shaping Tasks and Relationships at Work: Examining the Antecedents and Consequences of Employee Job Crafting. Unpublished Doctoral Dissertation, University of Pittsburgh, Pittsburgh.

[22] Demerouti, E., Bakker, A.B., Nachreiner, F. and Schaufeli, W.B. (2001) The Job Demands-Resources Model of Burnout. Journal of Applied Psychology, 86, 499-512. https://doi.org/10.1037/0021-9010.86.3.499

[23] Demerouti, E. and Peeters, M.C.W. (2018) Transmission of Reduction-Oriented Crafting among Colleagues: A Diary Study on the Moderating Role of Working Conditions. Journal of Occupational and Organizational Psychology, 91, 209-234. https://doi.org/10.1111/joop.12196

[24] Bruning, P.F. and Campion, M.A. (2018) A Role-Resource Approach-Avoidance Model of Job Crafting: A Multi-Method Integration and Extension of Job Crafting Theory. Academy of Management Journal, 61, 499-522. https://doi.org/10.5465/amj.2015.0604

[25] Prins, J.T., Van der Heijden, F.M.M.A., Hoekstra-Weebers, J.E.H.M., Bakker, A.B., Van de Wiel, H.B.M., Jacobs, B. and Gazendam-Donofrio, S.M. (2009) Burnout, Engagement, and Resident Physicians' Self-Reported Errors. Psychology, Health \& Medicine, 14, 654-666. https://doi.org/10.1080/13548500903311554

[26] Niavi, A. (2012) Job Crafting and Job Performance: A Research Diary. Unpublished Thesis, Department of Psychology, University of Crete, Heraklion.

[27] Agorastos, D. and Kayioglidis, D. (2016) Assigning Tasks as an Alternative Job Crafting Strategy in the Light of the Job Demands-Resources Model. Unpublished Thesis, Department of Psychology, Aristotle University of Thessaloniki, Thessaloniki.

[28] Schwarzer, R. and Jerusalem, M. (1995) Generalized Self-Efficacy Scale. In: Weinman, J., Wright, S. and Johnston, M., Eds., Measures in Health Psychology: A User's Portfolio. Causal and Control Beliefs, Nfer-Nelson, Windsor, 35-37.

[29] Grammatopoulou, E., Nikolovgenis, N., Skordilis, E., Evangelodimou, A., Haniotou, A., Tsamis, N. and Spinou, A. (2014) Validity and Reliability of General Self-Efficacy Scale in Asthma Patients. European Respiratory Journal, 44, 4314.

[30] Hu, Q., Schaufeli, W.B., Hessen, D.J., Salanova, M., Taris, T.W., Hakanen, J. and Shimazu, A. (2014) "East Is East and West Is West and Never the Twain Shall 
Meet": Work Engagement and Workaholism across Eastern and Western Cultures. Journal of Behavioral and Social Science, 1, 6-24.

[31] Xanthopoulou, D., Bakker, A.B., Kantas, A. and Demerouti, E. (2005) The Measurement of Burnout and Work Engagement: A Comparison of Greece and the Netherlands. New Review of Social Psychology, 7, 42-52.

[32] Zacher, H., Hacker, W. and Frese, M. (2016) Action Regulation across the Adult Lifespan (ARAL): A Meta-Theory of Work and Aging. Work, Aging and Retirement, 2, 286-306. https://doi.org/10.1093/workar/waw015

[33] Bakker, A.B. (2018) Job Crafting among Health Care Professionals: The Role of Work Engagement. Journal of Nursing Management, 26, 321-331. https://doi.org/10.1111/jonm.12551

[34] Bakker, A.B. and Demerouti, E. (2007) The Job Demands-Resources Model: State of the Art. Journal of Managerial Psychology, 22, 309-328. https://doi.org/10.1108/02683940710733115

[35] Petrou, P., Demerouti, E., Peeters, M.C.W., Schaufeli, W.B. and Hetland, J. (2012) Crafting a Job on a Daily Basis: Contextual Antecedents and the Effect of Work Engagement. Journal of Organizational Behavior, 33, 1120-1141.

https://doi.org/10.1002/job.1783 